\title{
Omentalização prostática em cães
}

Maricy APPARÍCIO'

Wilter Ricardo Russiano

VICENTE ${ }^{1}$

Eliandra Antônia PIREZ1

Giuliano Queiroz

MOSTACHIO ${ }^{1}$

Ana Paula Coelho RIBEIRO ${ }^{1}$

Gabriela Jayme COVIZZI ${ }^{1}$

Carla Renata Figueiredo

GADELHA $^{1}$

Marileda Bonafim

CARVALHO ${ }^{1}$

\section{Correspondência para:}

MARICY APPARÍCIO

Departamento de Reprodução e Medicina

Veterinária Preventiva

FaculdadedeCiências Agráriase Veterinárias

Universidade Estadual Paulista

Rod. Paulo Donato Castellane, s/n

14884-900-Jaboticabal-SP

maricyap@fcav.unesp.br

Recebido para publicação: 05/05/2005 Aprovado para publicação: 13/02/2006

\author{
1 - Departamento de Reprodução e Medicina Veterinária Preventiva \\ Serviço de Reprodução e Obstetrícia Veterinária e Serviço de Nefrologia \\ Veterinária da Faculdade de Ciências Agrárias e Veterinárias da \\ Universidade Estadual Paulista - Jaboticabal - SP
}

\section{Resumo}

Palavras-chave: Omentalização.

A próstata é a única glândula sexual nos cães e, embora seja encontrada em todos os mamíferos, sua importância clínica é maior no homem e nesta espécie animal devido à quantidade de afecções que os acometem. Diversas técnicas cirúrgicas têm sido utilizadas para o tratamento de cistos e abscessos prostáticos em cães, e há alguns anos foi relatado o primeiro uso da técnica de omentalização prostática para o tratamento de cistos e abscessos, com sucesso efetivo, e até o momento, não há informações de seu emprego no Brasil. Sendo assim, este trabalho teve como objetivo avaliar a recuperação e o período pós-operatório de animais submetidos a esta técnica, durante o período de 2002 a 2004. Foram estudados 17 machos, sendo 11 com cistos prostáticos, 4 com abscesso e 2 com cisto paraprostático. Quinze se recuperaram sem complicações, enquanto um apresentou incontinência urinária por dois dias após a cirurgia. Um animal veio a óbito em decorrência de septicemia preexistente. A baixa incidência de complicações e o curto período de hospitalização fazem da omentalização a cirurgia de escolha para o tratamento de abscessos e cistos prostáticos em cães.

\section{Introdução}

A próstata é a única glândula sexual dos cães. Ela é encontrada em todos os mamíferos, mas possui maior importância clínica no homem e no cão devido à quantidade de afecções que acometem estas espécies. As doenças prostáticas são comuns em cães idosos e podem se manifestar no que se denomina síndrome prostática, com sinais clínicos relacionados ao sistema urinário, digestório e locomotor, podendo estar presentes simultaneamente ou não ${ }^{1}$. Sinais clínicos mais comuns incluem: disúria, gotejamento de sangue pelo pênis acompanhado ou não de micção, hematúria e infecções urinárias não responsivas ao tratamento médico, tenesmo, fezes secas ou moles com formato laminar e dificuldade de locomoção ${ }^{2}$. Outros sinais menos específicos e característicos de infecções agudas, tais como hipertermia, letargia e vômito, também podem estar presentes ${ }^{3}$. As complicações relacionadas às afecções prostáticas incluem infecções urinárias recidivantes, insuficiência renal, hidronefrose e hérnia perineal ${ }^{1,3}$.

Os cistos prostáticos podem ser caracterizados como de retenção ou paraprostáticos. Os de retenção ocupam o parênquima e são causados pelo acúmulo de secreções prostáticas dentro do órgão como resultado de obstruções dos duc$\operatorname{tos}^{2,4}$. Os cistos paraprostáticos não têm comunicação com a próstata e alguns autores têm sugerido que sejam resquícios embrionários dos ductos de Müller 5 .

Os abscessos prostáticos geralmente são resultado de infecção bacteriana ascendente que ultrapassa os mecanismos de defesa da uretra e coloniza o parênquima prostático $^{6}$. Podem ser secundários a prostatite bacteriana supurativa, que leva a formação de microabscessos no parênquima, os quais se fundem formando um abscesso maior, ou ainda, como resultado 
da contaminação de cistos de retenção, paraprostáticos ou metaplásicos ${ }^{7}$. Os principais microorganismos envolvidos são Escherichia coli, Staphylococcal spp e Proteus sp $p^{6,8}$.

A orquiectomia bilateral é indicada como adjuvante no tratamento das afecções prostáticas, exceto nos animais com câncer prostático ${ }^{9}$. Naqueles com abscesso, mesmo em conjunto com terapia antimicrobiana, não tem apresentado resultado satisfatório devido à dificuldade das drogas em alcançar concentrações terapêuticas no tecido ${ }^{10,11}$. Esta talvez seja a principal razão para a variedade de técnicas cirúrgicas existentes para remover ou drenar os abscessos e cistos prostáticos, tais como, a marsupialização, ressecção local, prostatectomia subtotal e o uso do dreno de penrose ${ }^{12}$, e não cirúrgicas como a drenagem percutânea guiada por ultrasonografia ${ }^{13}$. No entanto, o cuidado pósoperatório intensivo, as complicações de longo prazo, bem como as recidivas associadas a esses procedimentos, inspiraram o desenvolvimento de uma nova técnica cirúrgica utilizando o omento.

Esta estrutura tem sido utilizada em vários procedimentos na medicina humana, os quais incluem cirurgias gastrointestinais, vasculares, e reconstrutivas ${ }^{14}$. $\mathrm{Na}$ medicina veterinária, a utilização do omento tem ocorrido por suas propriedades de adesão, armazenamento de gordura, e preenchimento do espaço morto ${ }^{14}$, contudo seu uso ainda é restrito.

Algumas propriedades do omento, tais como a capacidade de angiogênese, de livre movimentação na cavidade abdominal, e sua função imunológica, viabilizam sua utilização em procedimentos cirúrgicos, podendo ser usado para induzir a vascularização, permitir nova drenagem linfática, potencializar o processo cicatricial e adesão, facilitando a reparação tecidual ${ }^{4,11,15}$. Baseado nestes preceitos, White e Williams ${ }^{11}$ sugeriram que o omento pudesse ser utilizado como um dreno fisiológico nos abscessos prostáticos através da técnica de omentalização prostática. Dois anos mais tarde, sua aplicabilidade cirúrgica foi confirmada em cães com cistos de retenção prostática ${ }^{4}$.

Este trabalho relata a utilização da técnica de omentalização em 17 animais da espécie canina que apresentavam abscessos, cistos prostáticos e paraprostáticos, com o objetivo de avaliar a viabilidade, bem como a recuperação dos animais no período pósoperatório, cotejando estes resultados com os descritos para procedimentos convencionais, uma vez que ainda não há dados sobre seu emprego no Brasil.

\section{Materiais e Métodos}

Foram estudados 17 cães, sendo 11 com cistos prostáticos, 04 com abscessos e 02 com cistos paraprostáticos durante os anos de 2002 a 2004 (Tabela 1). Os animais foram atendidos no Hospital Veterinário "Governador Laudo Natel", na Faculdade de Ciências Agrárias e Veterinárias, da Unesp, campus de Jaboticabal e submetidos a exame físico completo que compreendia o toque retal associado à palpação transabdominal da glândula prostática, seguida de hemograma completo e exame bioquímico, radiográfico e ultra-sonográfico. Os cães que apresentavam alguma alteração na urina (cor, freqüência, ausência, etc), também foram submetidos à urinálise. Os cistos $\mathrm{e}$ abscessos foram identificados no exame ultra-sonográfico pela presença de cavitações com conteúdo, e posteriormente confirmados durante o procedimento cirúrgico.

Os animais receberam como medicação pré-anestésica levomepromazina $(0,5$ $\mathrm{mg} / \mathrm{kg}$ ), e foram induzidos com propofol $(5 \mathrm{mg} / \mathrm{kg}$ ), para que fossem intubados e submetidos a anestesia inalatória, utilizando isoflurano com fluxo diluente de $\mathrm{O}_{2}$ 100\% em circuito semi fechado. Foi realizada celiotomia caudal, com a incisão se estendendo da cicatriz umbilical até o púbis. A glândula prostática foi isolada utilizandose o afastador de Weitlaner ou o afastador auto-estático, e os cistos ou abscessos foram identificados. O conteúdo destas estruturas foi aspirado com o intuito de se evitar a 
Tabela 1 - Descrição dos animais, queixas clínicas e achados cirúrgicos dos 17 animais submetidos à técnica adaptada de omentalização prostática no Hospital Veterinário "Governador Laudo Natel", FCAV-UNESP, Câmpus de Jaboticabal, durante os anos de 2002 a 2004

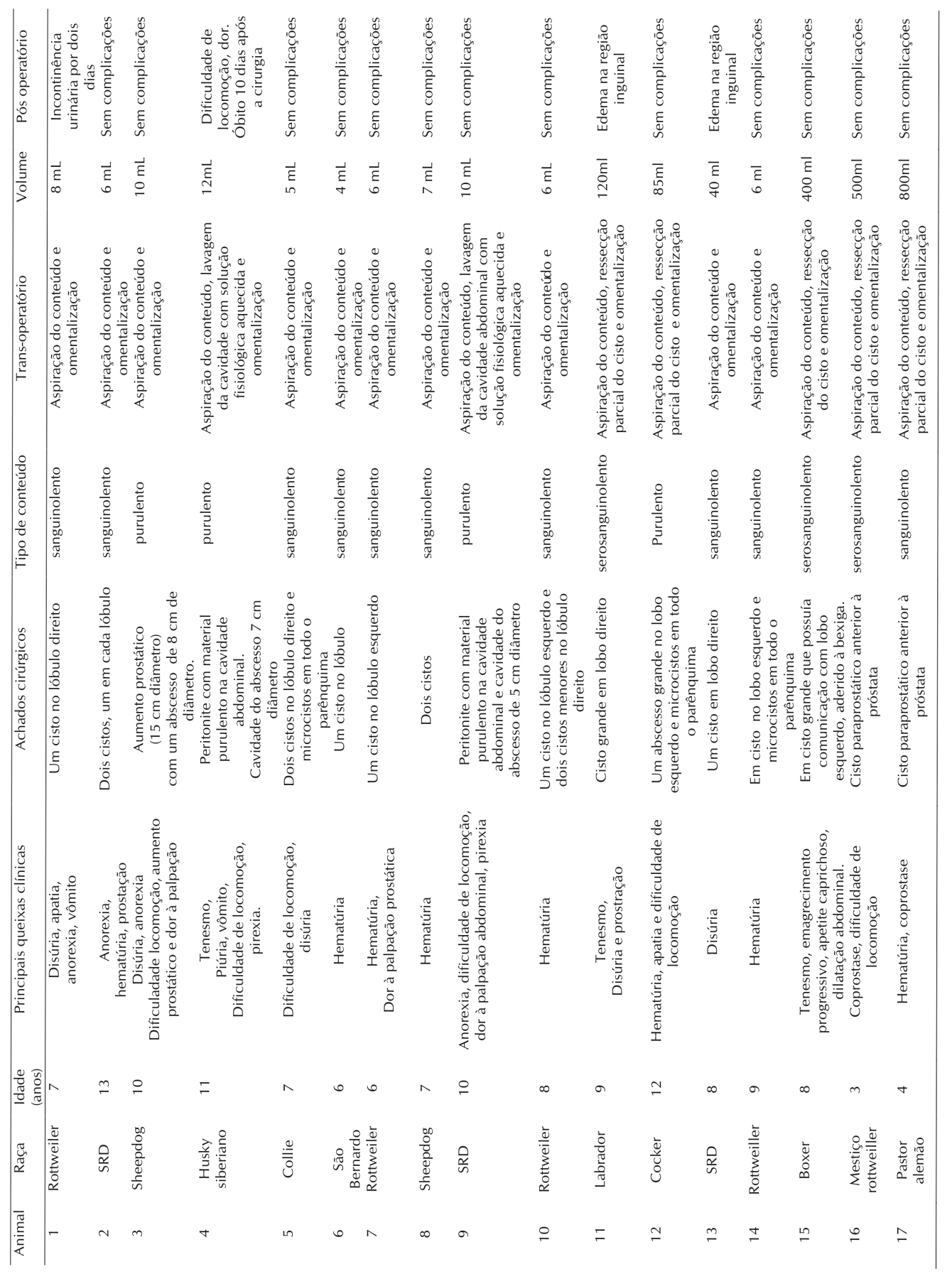


contaminação abdominal. A omentalização foi realizada utilizando-se técnica modificada por Verstegen (comunicação pessoal), em que uma incisão é feita na face ventral da glândula, em ambos os lobos prostáticos. As cavidades eram exploradas e, quando necessário, expandidas digitalmente, adjacente à uretra. Para que não houvesse lesão da uretra, a mesma era identificada por palpação da sonda uretral previamente colocada. A omentalização prostática foi realizada introduzindo o omento dentro das cavidades, em quantidade suficiente para o preenchimento de todo o espaço, sem que houvesse comunicação entre os dois lobos e, portanto, sem circundar a uretra, como foi descrito por White e Williams ${ }^{11}$ (Figura 1). Ato contínuo, esta estrutura era fixada com sutura contínua simples utilizando-se fio de sutura vicryl $3 / 0$ ou 4-/0, englobando sempre o omento e a cápsula prostática. Nos animais que apresentavam abscesso prostático, foi realizada lavagem da cavidade abdominal com solução fisiológica préaquecida. Nos cães com grandes cistos e também naqueles com cistos prostáticos, foi realizado primeiro a ressecção e posteriormente a omentalização, com o mesmo tipo de sutura e fio descrito acima. A sutura da musculatura e peritônio foi realizada com vicryl 0 , ponto tipo sultan, e a redução do espaço morto com vicryl 2/0. A cútis foi suturada com nylon $2 / 0$, pontos em $\mathrm{U}$. Os machos não castrados também foram submetidos a orquiectomia bilateral.

No período pós-operatório, os animais foram tratados com enrofloxacina $5 \%{ }^{6}(5 \mathrm{mg} / \mathrm{kg}$ IM a cada $12 \mathrm{~h}$, até receberem alta), fluidoterapia (solução ringer lactato ${ }^{4}$ ) e buprenorfina ${ }^{1}(5 \mathrm{mg} / \mathrm{kg}$ IM cada $12 \mathrm{~h}$, por dois dias consecutivos). Os cães que apresentavam anorexia e vômito também receberam metoclopramida ${ }^{3}(0,2 \mathrm{mg} / \mathrm{kg} \mathrm{ca}-$ da 8 horas $)$ e ranitidina ${ }^{10}(2,2 \mathrm{mg} / \mathrm{kg}$ cada 8 horas). Na ferida cirúrgica era aplicado somente anti-séptico (Povidine). Os animais eram levados pra passear duas vezes ao dia para que fosse avaliada a micção e o caminhar, principalmente o movimento dos membros pélvicos. Qualquer dificuldade na locomoção que caracterizasse dor ou desconforto era anotada. Nos cães com abscessos, a administração do antibiótico era continuada pelo proprietário por mais uma semana quando não havia uma cistite associada, do contrário, a antibioticoterapia se estendia por pelo menos 15 dias. Os animais retornaram para a retirada dos pontos e exames complementares dez dias após a cirurgia. Novas avaliações foram feitas um mês e um ano após a cirurgia.

\section{Resultados}

Após a cirurgia, quinze cães recuperaramse rapidamente. Um único animal não apresentou remissão dos sinais clínicos, com o quadro agravando diariamente até culminar com o óbito 10 dias após a cirurgia. Este cão já chegou ao hospital debilitado e com dificuldade de locomoção, e na cirurgia puderam-se constatar sinais de peritonite causados provavelmente pelo extravasa-mento de conteúdo purulento oriundo do abscesso prostático. Um outro animal apre-sentou incontinência urinária por dois dias após a cirurgia, tendo cessado completa-mente no terceiro dia.

Os animais começaram a se alimentar em média 48 horas após a cirurgia, quando então receberam alta. Dois deles apresentaram edema na região inguinal, o qual foi amenizado com Reparyl ${ }^{\circledR}$ gel e massagem no local duas vezes ao dia. No dia seguinte a cirurgia os animais já se levantavam e não aparentavam desconforto ao caminhar, com exceção do cão que veio a óbito, o qual caminhava com os membros pélvicos rígidos e com a coluna levemente curvada. Não houve registro de deiscência dos pontos ou sinais de infecção e os cães apresentavam-se hígidos no exame físico realizado uma semana após a cirurgia. Nas outras duas avaliações (um mês e um ano após a cirurgia) os cães continuavam bem, sem sinais clínicos ou alterações nos exames físicos e complementares (hemograma, bioquímico e ultrasonográfico). 


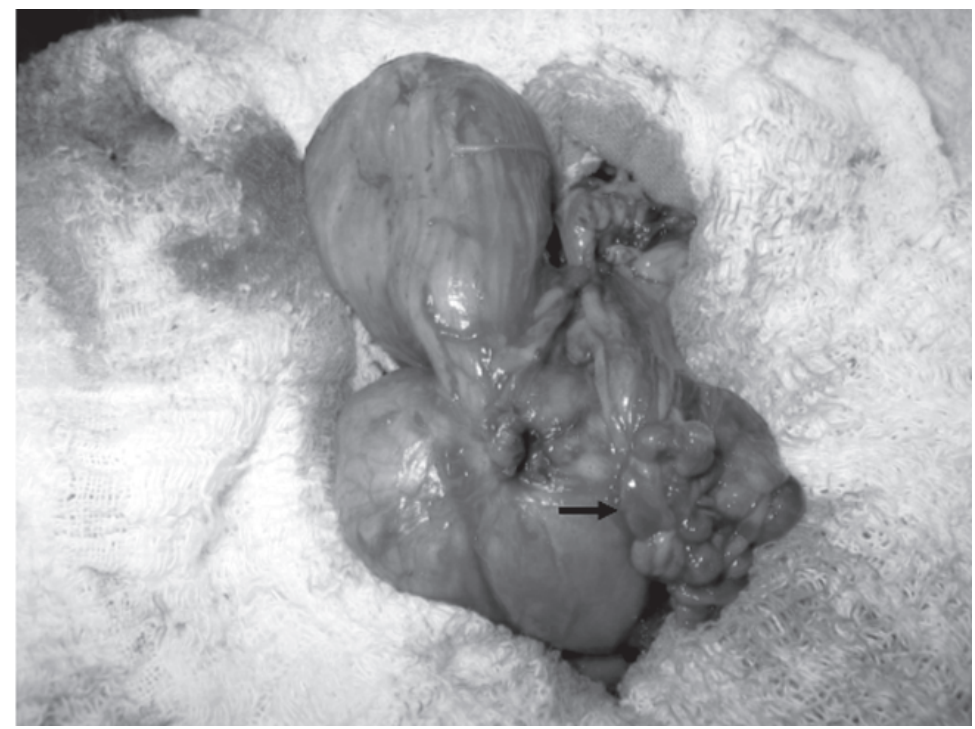

Figura1 - A seta indica a omentalização prostática realizada no lobo esquerdo

\section{Discussão}

As afecções da próstata são muito comuns em cães de meia idade e idosos, e entre elas a mais comum é a hiperplasia benigna do órgão, seguida pelos cistos e abscessos, podendo ou não estar associados. Em nosso estudo, quatro cães apresentavam abscessos prostáticos, sendo que dois já tinham sinais de septicemia. Os sinais clínicos apresentados por estes quatro animais eram similares aos característicos de prostatite bacteriana aguda e abscedação sem ruptura ${ }^{4,6}$ mesmo com os animais 4 e 9 já apresentando ruptura do abscesso. Exames complementares, como hematológico e bioquímico, podem auxiliar no diagnóstico, sendo que muitos casos de abscesso prostático se caracterizam por uma leucocitose com neutrofilia ${ }^{6,16}$ como ocorreu nos cães 4, 9 e 12. O animal 3 apresentou somente leucocitose e creatinina elevada, provavelmente devido a retenção urinária (disúria); enquanto os cães 4, 9 e 12, apresentaram valores normais para o perfil bioquímico. Os cães com cistos prostáticos (cães 1, 2, 58, 10, 11 e 13,14), mesmo apresentando alterações urinárias, apresentaram valores normais tanto para o exame hematológico, quanto para o perfil bioquímico. $\mathrm{O}$ animal
15 apresentava tenesmo ao defecar, provavelmente ocasionado pela compressão que o cisto fazia no reto, e não apresentava alterações nos exame laboratoriais, assim como os cães com cistos paraprostáticos ${ }^{16,17}$.

Em um estudo com 92 cães com abscessos prostáticos tratados por drenagem utilizando o dreno de Penrose, a mortalidade foi de $21 \%$ com sepsis e choque ocorrendo em um terço dos animais ${ }^{17}$. Em nosso estudo, dois cães apresentaram ruptura do abscesso previamente à intervenção cirúrgica com sinais de septicemia, sendo que um deles veio a óbito 10 dias após. Embora seja difícil chegar a alguma conclusão definitiva, acreditamos que a drenagem e a lavagem peritoneal, associadas à antibioticoterapia e omentalização não foram suficientes para controlar a peritonite e a septicemia previamente instalada neste animal, enquanto que no cão 9 o quadro não era tão severo, e talvez, por esta razão ele tenha se recuperado sem maiores complicações.

Os cães neste estudo ficaram hospitalizados por um período médio de 2 dias, quando já estavam se alimentando e não mais apresentavam sinais clínicos, com exceção do cão 4 que precisou de cuidados pós operatórios intensivos e fluidoterapia endovenosa, permanecendo internado até seu 
óbito. Contrariamente, a marsupialização, a drenagem utilizando os drenos de Penrose e a prostatectomia necessitam de um cuidado pós-operatório prolongado além das duas primeiras necessitarem de um manejo cuidadoso e por um período prolongado das feridas de drenagem, podendo chegar a 21 dias no caso dos drenos e até 4 meses nos animais marsupializados ${ }^{17,18}$. Em nosso estudo, o único manejo realizado foi a aplicação de antiséptico na ferida cirúrgica por 7 dias consecutivos e, em dois cães que apresentaram edema na região inguinal, também foi necessário massagear a região com Reparylâ gel, com regressão visível do edema ao terceiro dia.

Reabscedação é uma complicação comum tanto da marsupialização como da drenagem ventral ${ }^{17} \mathrm{e}$ acomete aproximadamente um quinto dos animais ${ }^{9}$. A drenagem nestes procedimentos pode continuar por vários meses ocasionada provavelmente por uma infecção prostática persistente ou uma infecção ascendente ${ }^{6}$. A incontinência urinária é a complicação mais comum da prostatectomia total e subtotal ${ }^{19}$, ocorrendo em mais de $90 \%$ dos cães ${ }^{9}$, sendo também freqüente na ressecção dos cistos prostáticos, juntamente com a retenção urinária ${ }^{20}$. No entanto, a freqüência e severidade da incontinência podem ser minimizadas após a prostatectomia subtotal com a utilização do aspirador ultra-sônico ${ }^{9,21}$ o qual nos permite eliminar o tecido prostático sem danificar a uretra e nervos; porém seu custo é elevado e não está disponível na maioria dos centros cirúrgicos do Brasil.

A omentalização, por sua vez, apresenta baixa incidência de incontinência no período pós-operatório e em longo prazo e, de acordo com White e Williams ${ }^{11}$, isso é devido a algumas razões: pequena manipulação da inervação do trígone e da uretra prostática; risco mínimo de ruptura uretral; capacidade do omento de estimular a angiogênese em lugares onde sua viabilidade está diminuída; e capacidade do omento de fornecer um suporte vascular adicional que pode servir para prevenir uma ruptura iminente da uretra prostática causada pelos abscessos ou cistos adjacentes. Somente um cão (animal 1) apresentou uma incontinência transitória após a cirurgia que durou dois dias, a qual pode ter se desenvolvido secundariamente a uma bexiga atônica ${ }^{22}$.

A omentalização que nós utilizamos aqui difere da descrita por White e Williams ${ }^{11}$ e também da relatada por Pratschke e Bellenger ${ }^{23}$. Na primeira técnica o tecido entre as cavidades direita e esquerda do abscesso era rompido tanto dorsal como ventralmente à uretra prostática, para que o omento pudesse ser introduzido de modo a circundá-la, enquanto que Pratschke e Bellenger fizeram somente uma conexão entre as cavidades do abscesso. Nós acessamos a próstata (capsulectomia) ventralmente, não lateralmente como nas outras duas técnicas, e o omento foi colocado dentro da próstata lateralmente a uretra, não ao redor dela, como foi descrito por White e Williams ${ }^{11}$, nem com uma conexão ventral entre as cavidades, como relatado por Pratschke e Bellenger ${ }^{23}$. Embora as três técnicas preencham todo o espaço dentro das cavidades prostáticas, a técnica adaptada que nós utilizamos não coloca o omento ao redor da uretra, prevenindo-se assim uma possível estenose uretral.

\section{Conclusões}

A técnica de omentalização empregada neste estudo proporcionou um acesso mais adequado e fácil à próstata, reduzindo-se a manipulação do órgão e consequentemente, causando o mínimo de lesão nos componentes neurovasculares da glândula. Esta característica favoreceu melhor recuperação do animal, sem complicações pós-operatórias e possibilitou a redução do período de hospitalização, diminuindo-se assim, o custo do tratamento, normalmente elevado nos procedimentos convencionais.

Embora o número de animais utilizados não tenha sido expressivo, ao 
cotejar nossos resultados com os descritos na literatura consultada para a remoção de cistos e abscessos prostáticos, podemos inferir que a omentalização é a que apresentou os menores índices de complicações pós- operatórias, curto período de hospitalização e cuidados pós-operatórios simples. Assim, em nossa opinião, deve ser considerada como tratamento eletivo para a remoção de cistos e abscessos prostáticos.

\title{
Prostatic omentalisation in dogs
}

\begin{abstract}
The prostate is the only acessory sex gland in the male dog and, although the prostate is found in all mammals, it has a great importance in men and dogs due to the frequency of disorders. Several techniques have been employed for the treatment of prostatic cysts and abscesses and, a few years ago, it was successfully described the use of prostatic omentalisation for this purpose; until now, there are no data about this surgery in Brazil. So, the aim of this study was to evaluate the animal recovery, as well as the post operative period of dogs that underwent prostatic omentalisation, from 2002 to 2004. It was evaluated $11 \mathrm{dogs}$ with prostatic cysts, 4 dogs with prostatic abscesses and 2 with paraprostatic cysts. Fifteen dogs had an uneventful recovery while one dog had a minor incontinence for two days. One dog died due to a previous long term sepsis. The low incidence of post operative complications and brief hospitalization period make omentalisation the surgery of choice for the treatment of prostatic cysts and abscess.
\end{abstract}

Key-words:

Omentalisation.

\section{Referências}

1 CHAFRAUX, S. Pathologie de la prostate du chien. Recherche de medécine vetérinarie, v.155, p.421-427, 1979.

2 JOHNSTON, D. S.; KUSTRITZ, M. V. R.; OLSON, P. N. S. Disorders of the Canine Prostate. In: JOHNSTON, D.S.; KUSTRITZ, M.V.R.; OLSON, P.N.S. Canine and feline theriogenology. Philadelphia: Saunders, 2001. p. 337-355.

3 COTARD, J. P. Syndrome prostatique chez le chien. Le Point Vétérinaire, v. 11, n. 52, p. 61-66, 1980.

4 BRAY, J. P.; WHITE, R. A. S.; WILLIAMS, J. M. Partial Ressection and Omentalization: A New Technique for Management of Prostatic Retention Cysts in Dogs. Veterinary Surgery, v. 26, p. 202-209, 1997.

5 VERSTEGEN, J. P. Conditions of the male. In: Simpson, G. M.; England, G. C. M.; Harvey, M. (Ed.). BSAVA manual of small animal reproduction and neonatology. British Small Animal Veterinary Association,1998. p. 78-79.

6 BASINGER, R.R.; LUTHER, P.B. Prostatic disease. In: $B O J R A B, M$. J. Disease mechanisms in small animal surgery. 2. ed. Philadelphia: Lea \& Febiger, p.1993. 539-544.
7 HOFFER, R. E.; DYKES, N. L.; GREINER, T. P. Marsupialization as a treatment for prostatic disease. The Journal of American Animal Hospital Association, v. 13, p. 98-104, 1977.

8 ZOLTON, G.M. Surgical techniques for the prostate. Veterinary Clinicas of North America, v. 9, p. 349355, 1979.

9 RAWLINGS, C. A. Surgery of the Prostate. In: BOJRAB, M. J. Current techniques in small animal surgery. 4 ed. Maryland: Williams \& Wilkins,1998. p.479-487.

10 DAVIS, L. E. Management of canine bacterial prostatitis. Journal of the American Veterinary Medical Association, v. 182, p. 292, 1983.

11 WHITE, R. A. S.; WILLIAMS, J. M. Intra-capsular prostatic omentalization- a new technique for management of prostatic abscessation. Veterinary Surgery, v. 24, p. 390-395, 1995.

12 HEDLUND, C. S. Surgery of the Reproduction and Genital Systems. In: FOSSUM, T.W. Small Animal Surgery. St Louis: Mosby, 1997. p. 534-537, 552-562.

13 FROES, T. R.; GONZALES, J. R. M.; KANAYAMA, L. M.; JORGE, R.C.; IWASAKI, M. Ultra-sonografia intervencionista-drenagem percutânea de lesões cavitárias e cistos prostáticos em cães. Clínica Veterinária, n. 47, p. 34-40, 2003. 
14 HOSGOOD, G. The omentum-The Forgotten Organ: Physiology and Potential Surgical Applications in Dogs and Cats. Compendium on Continuous Education, v. 12, n. 1, p. 45-49, 1990.

15 GRECA, F. H.; BIONDO-SIMÕES, M.L.P.; SOUZA FILHO, Z. A . Ação do omento na cicatrização de anastomoses colônicas. Estudo experimental em ratos. Acta Cirúrgica Brasileira, v.13, n. 3, p. 172-176, 1998.

16 MATTHIESEN, D. T.; MARRETA, S. M. Complications associated with the surgical treatment of prostatic abscessation. Problems in Veterinary Medicine, v. 1, p. 63-73, 1989.

17 MULLEN, H. S.; MATTHIESEN, D. T.; SCAVELLI, T. D. Results of surgery and postoperative complications in 92 dogs treated for prostatic abscessation by a multiple Penrose drain technique. Journal of the American Animal Hospital Association, v. 26, p. 369-379, 1990.

18 HARDIE, E. M.; BARSANTI, J. A.; RAWLINGS, C. A. Complications of prostatic surgery. Journal of the American Animal Hospital Association, v. 20, p. 5055, 1982.

19 BASINGER, R. R.; RAWLINGS, C. A.; BARSANTI, J. A.; OLIVER, J.E. Urodynamic alterations associated with clinical prostatic diseases and prostatic surgery in 23 dogs. Journal of the American Animal Hospital Association, v. 25, p. 385, 1989.

20 WHITE, R. A. S.; HERRTAGE, M. E.; DENNIS, R. The diagnosis and management of paraprostatic and prostatic retention cysts in the dog. Journal of Small Animal Practice, v. 28, p. 551, 1987.

21 RAWLINGS, C. A.; QUANDT, J. E.; DOWNS, M. O. Use of partial prostatectomy for treatment of prostatic abscesses and cysts in dogs. Journal of the American Veterinary Medical Association, v. 211, n. 7, p. 868-871, 1997.

22 STONE, E. A.; BARSANTI, J. A. Urologic surgery of the dog and cat. Philadelphia: Lea \& Febiger, 1992. 215-234.

23 PRACTSCHKE, K. M.; BELLENGER, C. R. Treatment of prostatic abscessation in a dog by intracapsular prostatic omentalisation, Irish Veterinary Journal, v. 52, n. 3, p. 145-148, 1999. 